\title{
PERAN DIGITAL PARENTING TERHADAP PERKEMBANGAN BERPIKIR LOGIS ANAK USIA 5-6 TAHUN DI RA BUNAYYA GIWANGAN
}

\author{
Sri Maisari \\ Universitas Islam Negeri Sunan Kalijaga Yogyakarta \\ Email: maisari568@gmail.com \\ Sigit Purnama \\ Universitas Islam Negeri Sunan Kalijaga Yogyakarta \\ Email: sigit.purnama@uin-suka.ac.id
}

\section{Article received: 03 Maret 2019 Review Process:}

Article Published:

\begin{abstract}
Kids can not be separated with the advances in digital technology. Parents play an important role in caring for children who know the gadget. The use of gadgets in children can be used as an educational tool that stimulates children to think logically. This study aims to describe the application of digital concept of parenting the parents of children aged 5-6 years in RA Bunayya digital Giwangan and know the role of parenting to the development of logical thinking of children aged 5-6 years. The method used is qualitative descriptive analysis approach. Subjects in the study that parents and children ages 5-6, amounting to 5 people. Determination of the subject based on the consideration of parents who apply digital concept of parenting. The results showed that the application of digital parenting concepts include: applying the rules and agreements related to the use of gadgets, guiding and assisting children, using parental control, and balance the child's digital world with the real world; and digital parenting role against logical thinking of children include: education as well as entertainment for children; stimulating logical thinking; control, supervise, guide the child and as an attempt to avoid a child addicted to gadgets.
\end{abstract}

Keywords: digital concept of parenting, children aged 5-6 years, to think logically

\begin{abstract}
Abstrak
Anak tidak dapat dipisahkan dengan kemajuan teknologi digital. Orang tua berperan penting dalam mengasuh anak yang telah mengenal media digital khusunya gadget. Penggunaan gadget pada anak dapat dijadikan sebagai sarana edukasi dan menstimulasi berpikir logis anak. Penelitian ini bertujuan mendeskripsikan penerapan konsep digital parenting yang dilakukan orang tua terhadap anak usia 5-6 tahun di RA Bunayya Giwangan dan mengetahui peran digital parenting terhadap perkembangan berpikir logis anak anak usia 5-6 tahun. Metode yang digunakan adalah kualitatif dengan pendekatan analisis deskriptif. Subjek yang diteliti yaitu orang tua dan anak usia 5-6 yang berjumlah 5 orang. Penentuan subjek berdasarkan pertimbangan orang tua yang menerapkan konsep digital parenting. Hasil penelitian didapatkan bahwa penerapan konsep digital parenting meliputi: menerapkan aturan dan kesepakatan terkait penggunaan gadget, membimbing dan mendampingi anak, menggunakan parental control, dan menyeimbangkan dunia digital anak dengan dunia nyata; dan peran digital parenting terhadap berpikir logis anak meliputi: sebagai edukasi sekaligus hiburan bagi anak; menstimulasi berpikir logis; mengontrol, membimbing anak dan sebagai usaha untuk menghindari kecanduan gadget.
\end{abstract}

Kata kunci: konsep digital parenting, anak usia 5-6 tahun, berpikir logis 


\section{Pendahuluan}

Kemajuan teknologi menyebabkan penggunaan internet semakin meningkat. Berdasarkan laporan WeAreSocial tahun 2018 terdapat fakta mencengangkan. Fakta tersebut mengenai penggunaan internet dunia yang telah mencapai 4,021 milyar orang. Ini artinya lebih dari setengah manusia di dunia telah menggunakan internet. Sama halnya dengan kondisi di Indonesia, jumlah pengguna internet di Tanah Air mencapai 132 juta orang. Jumlah tersebut menunjukkan bahwa lebih dari 50\% penduduk Indonesia telah mengakses internet. Sementara itu dari laporan yang sama, dijelaskan dari ratusan juta pengguna internet di Indonesia tersebut 60\% nya telah mengakses internet dengan smartphone atau gadget (Ramadhan, 2018). Pengguna internet dari berbagai kalangan baik anak usia dini, kanak-kanak (masa pertengahan dan akhir), remaja, dewasa maupun lansia awal (46-55 tahun). Fungsi penggunaan gadget di kalangan anak usia dini tidak sama seperti orang dewasa untuk googling, blog, media sosial, vlog, dan aplikasi lainnya, tetapi anak lebih menggunakannya untuk bermain game, mendengarkan lagu, dan menonton film/video.

Namun begitu disayangkan, saat ini lingkungan bermain anak telah digantikan oleh gadget. Mereka yang seharusnya menikmati dunia bermain dengan teman-temannya, kini menghabiskan waktu bersama gadget. Durasi anak usia 3-7 tahun menggunakan gadget adalah maksimal 2 jam/hari. Gadget sebenarnya baik-baik saja jika digunakan seperlunya (tidak terlalu lama), untuk hal yang positif dan di bawah kendali orang tua. Namun sebaliknya, jika penggunaan terlalu lama dan tidak di bawah kendali orang tua, maka akan berkonskuensi terhadap perkembangan dan pertumbuhan anak (Chassiakos, dkk, 2016). Karena pada usia dini perkembangan otak anak mengalami lompatan dan berkembang sangat pesat, yaitu mencapai $80 \%$ sebagaimana yang dikemukakan oleh Bloom (Bloom, 1986, p.73). Sehingga masa ini seharusnya dimaksimalkan untuk pertumbuhan dan perkembangan anak melalui interaksi dunia nyata, bukan dunia maya.

Hal tersebut sangat penting diperhatikan orang tua dalam mendidik anak. Pemberian gadget dimaksudkan agar anak nyaman di rumah, hiburan dan edukasi. Hasil penelitian yang dilakukan oleh The Asian Parent Insights pada November 2014 dalam Tesa Alia, sebanyak 98\% dari 2.714 orang tua di Asia Tenggara yang mengikuti penelitian ini mengizinkan anaknya untuk mengakses teknologi berupa komputer, smartphone, atau televisi. Penelitian ini dilakukan terhadap 2.714 orang tua di Asia Tenggara yang memiliki anak berusia 3-8 tahun. Para orang tua peserta penelitian ini berasal dari Singapura, Malaysia, Thailand, Indonesia, dan Filipina. Dari hasil survei tersebut kebanyakan orang tua memperbolehkan anaknya bermain gadget untuk tujuan edukasi. Namun kenyataannya menurut hasil survei sebagian besar putra-putri mereka menggunakan gadget/tablet tersebut untuk tujuan hiburan seperti game (Alia, 2018).

Berdasarkan data tersebut orang tua memberikan gadget sebagai edukasi. Namun, kenyataannya di lapangan anak usia dini menggunakan gadget sebagai hiburan, seperti game. Nuswantoro., dkk dari Global Medical and Health Communication mengemukakan penggunaan gadget dapat mempengaruhi kualitas penglihatan, perkembangan sosial, emosional dan fisik-motorik, neurologi, kognitif, moral, bahasa, anak usia dini. Berbagai permasalahan yang ditemukan dari penggunaan gadget terlalu lama bagi anak. penggunaan gadget juga dapat berpengaruh baik pada perkembangan kognitif anak 
terutama aspek berpikir logis anak. Hal ini melalui tontonan dan game edukasi yang diakses anak (Alucyna, 2018).

Orang tua tidak mungkin melarang anaknya menonton televisi atau bermain gadget. Pengasuhan orang tua terhadap digital sangat penting dilakukan agar dapat menyeimbangkan interaksi anak dengan dunia nyata, lingkungan, dan menstimulasi berpikir anak. Oleh karena itu, orang tua perlu mengenal pengasuhan digital atau digital parenting agar penggunaan gadget pada anak tidak berpengaruh negatif terhadap perkembangan berpikir (Laely, dkk, 2017).

Penting bagi orang tua mengetahui cara mengasuh anak yang kesehariannya menggunakan gadget (digital parenting). Peneliti melakukan penelitian di RA Bunayya yang terletak di jl. Mamiri No 3 Malangan Giwangan, Umbulharjo 7, Yogyakarta. RA Bunayya Giwangan merupakan salah satu RA yang memiliki program digital parenting. Program digital parenting ini rutin diadakan sebulan sekali. Berdasarkan masalah yang terjadi terkait digital parenting terhadap perkembangan berpikir logis, maka yang menjadi fokus penelitian ini adalah: 1) penerapan konsep digital parenting yang dilakukan orang tua terhadap anak usia 5-6 tahun di RA Bunayya Giwangan; dan 2) peran digital parenting terhadap berpikir logis anak usia 5-6 tahun di RA Bunayya Giwangan.

\section{Penerapan Konsep Digital Parenting}

Digital parenting menurut Jenifer merupakan strategi pengasuhan orang tua terkait aturan penggunaan perangkat digital baik online maupun offline untuk melindungi keselamatan anak dari ancaman penggunaannya (Rode, 2009). Digital parenting mencakup kegiatan orang tua memberikan batasan yang jelas, membimbing dan mengawasi anak dalam menggunakan media digital (Sukiman, 2016). Orang tua dan anak memerlukan kesepakatan seputar penggunaan media digital, memanfaatkan program/aplikasi yang mendidik terkait aspek perkembangan anak, bukannya melarang anak menggunakan gadget. Hal ini tidak berarti orang tua melarang anak sepenuhnya menggunakan digital, tetapi memberi aturan dan batasan penggunaan yang jelas.

Batasan screen time anak terhadap media digital yang dikemukakan oleh AAP (American Academy of Pediatrics') adalah 2 jam per hari. Anak usia di bawah 2 tahun dianjurkan agar tidak menatap layar digital atau 0 menit. Anak usia 2-5 tahun batas screen time mereka adalah maksimal 1 jam per hari. Sedangkan untuk anak usia 6-12 tahun batas screen time mereka adalah maksimal 2 jam per hari. Penetapan screen time ini berdasarkan penelitian yang dilakukan di Amerika terkait "Tantangan, Resiko, dan Manfaat (Keuntungan) dari Penggunaan Media Digital terhadap Orang Tua dan Anak-Anak pada Tahun 2016" ( Mascheroni, dkk, 2018).

Orang tua memberikan perlindungan terhadap anak di lingkungan real maupun digital. Peran orang tua sebagaimana yang telah dijelaskan dalam konteks ini menunjukkan konsep pengasuhan digital atau digital parenting (Yurdakul, dkk, 2013). Dengan demikian, digital parenting merupakan bagaimana orang tua mendidik anak di era digital.

Saat ini di Indonesia melalui Kemendikbud tengah menggalakkan parenting di era digital. Banyak modul yang keluarkan oleh Kemendikbud terkait hal ini. Dyna Herlina (Herlina, dkk, 2018) ahli psikolog dan sosial mengemukakan hal-hal yang harus dilakukan 
orang tua terhadap anak dalam pengasuhan digital atau digital parenting adalah sebagai berikut:

a. Mendampingi anak mengakses gadget

Orang tua sebaiknya selalu besama bersama anak ketila ia menggunakan gadget. Hal ini dilakukan untuk dua kepentingan utama yaitu menegosiasikan waktu akses dan memilih media saluran.

b. Mengarahkan penggunaan perangkat dan media digital dengan jelas Jika anak sudah terpapar perangkat digital lebih baik untuk mengarahkan dengan komunikasi efektif untuk memutuskan berapa lama dan kapan anak-anak dapat menggunakannya. Perlu ada kesepakatan penggunaan perangkat digital antara orang tua dan anak.

c. Memahami informasi yang disediakan media digital

Pemahaman dilakukan dengan meggunakan kerangka moral dan rasional setiap keluarga. Agar pola pengasuhan dapat berfungsi sebagai pendidikan, maka orang tua mendiskusikan apa yang didapatkan anak media digital atau gadget tersebut. Ada banyak konten kontroversial seperti kecelakaan yang berdarah-darah. Konten seperti ini tidak pantas ditonton anak namun jika sudah terlanjur mengaksesnya maka orang tua perlu memberi pemahaman untuk menghindari, tidak pantas menyebarluaskan dan mnegantisipasi dampaknya bagi perasaan dan pikiran anak.

d. Mengimbangi waktu penggunaan perangkat digital dengan interaksi dunia nyata Hal ini sangat penting dilakukan orang tua agar anak tetap dapat berinteraksi dengan lingkungan sekitarnya. Misalnya, dengan mengenalkan pengalaman dunia nyata seperti aktivitas kesenian; kegiatan luar ruangan; olahraga; membaca interaktif; berinteraksi dengan temannya, bermain permainan tradisional dan lain sebagainya.

e. Pinjamkan anak perangkat digital sesuai keperluan

Orang tua dilarang keras memberi atau membeli perangkat digital khusus buat anak. Perilaku seperti ini nantinya akan memunculkan dampak negatif dari penggunaan digital. Dengan demikian orang tua disarankan hanya meminjamkan perangkat digital seperti ipad, gadget, dan komputer agar mereka bisa belajar mengendalikan diri dan belajar menggunakannya bersama keluarga.

f. Pilihkan program/aplikasi positif

Orang tua perlu mengidentifikasi program/aplikasi yang memiliki edukasi misalnya aplikasi pengenalan abjad, huruf hijaiah atau berhitung, piano, lagu anak-anak, belajar wudhu dan sholat, mewarnai dan lain-lainya. Hal ini dapat memberikan dampak positif bagi aspek perkembangan anak.

g. Mendampingi dan meningkatkan interaksi

Orang tua perlu mendampingi dan berinterksi dengan anak selama penggunaan media digital. Dampingi anak saat berselancar di dunia maya menggunakan satu perangkat digital pada kesempatan yang sama dapat diwujudkan dalam interaksi nyata sebagai aktifitas keluarga.

h. Gunakan perangkat digital secara bijaksana

Orang tua merupakan model anak dalam keluarga. Oleh karena itu orang tua perlu bijaksana menggunakan perangkat digital selama berinteraksi dengan anak. Orang tua yang kurang bijaksana menggunakan perangkat digital menjadi lebih 
kasar atau terkadang mengabaikan anak. Dan hal yang sangat penting adalah tidak menggunakan perangkat digital sebelum tidur.

i. Telusuri aktivitas anak di dunia maya

Orang tua dapat memonitor situs web yang pernah dikunjungi, dan pastikan anak tidak mengunjungi situs yang tidak sesuai usia. Saat ini banyak program piranti lunak penyaring (web-filtering) yang dapat membantu orang tua dalam melakukan scan ataupun memblok alamat website yang mengandung fitur yang tidak sesuai dengan perkembangan anak.

Orang tua dapat memanfaatkan gadget sebagai sarana menstimulasi anak berpikir logis. Contohnya game edukasi seperti berhitung, balon/kubus warna, mencetak kue; atau berbagai video edukasi lainnya seperti Upin-Ipin, Dora, viedo lagu anak-anak, dan sebagainya.

\section{Perkembangan Berpikir Logis}

Aspek perkembangan kognitif dalam Permendikbud Nomor 137 Tahun 2014 adalah belajar dan pemecahan masalah, berpikir logis dan berpikir simbolik (Kurniasari, dkk, 2013). Mega mengungkapkan berpikir logis pada anak usia prasekolah bahwa tugas perkembangan anak usia dini (dimensi berpikir logis) adalah mengumpulkan dan membuat informasi yang masuk akal dengan menggabungkan, membedakan, mengklasifikasikan, menghitung, mengukur, dan mengenal pola. Anak menggunakan pemikiran logis untuk mengorganisasikan dunia mereka secara konseptual dan memperoleh pemhaman yang lebih baik bagaimana itu bekerja (Minutos, 2016.

Berpikir logis anak usia 5-6 tahun dalam Permendikbud No 137 Tahun 2014 mencakup a) mengenal perbedaan ukuran berdasarkan "lebih dari"; kurang dari"; b) mengurutkan benda berdasarkan ukuran dari besar ke kecil; c) mengurutkan benda berdasarkan ukuran dari kecil ke besar; d) membedakan benda berdasarkan ukuran banyak-sedikit; e) mengelompokkan benda berdasarkan warna, f) menyusun benda berdasarkan bentuk; g) menyebutkan hubungan sebab-akibat tentang lingkungan; $h$ ) mengurutkan benda berdasarkan bentuk; i) mengenal pola $A B C D-A B C D$; $)$ menunjukkan inisiatif memilih permainan; dan penjumlahan secara sederhana (Permendikd, Nomor 137, 2014).

Berhubungan berpikir logis merupakan aspek dari perkembangan kognitif. Maka teori yang digunakan adalah teori kognitif. Dalam pembahasan ini peneliti menggunakan satu teori ahli yaitu Jean Piaget.

Pra-operasional (The Stage of Preoperational Thought). Ini merupakan tahap ke-2 perkembangan kognitif Piaget yang berlangsung antara usia 24 bulan -7 tahun. Pada usia 2 tahun anak mulai dapat menggunkan simbol atau tanda untuk merepresentasikan suatu benda yang tidak tampak di hadapannya. Masa ini anak mulai telah mewakili tahap representasi-represantsi mental dan memiliki pertimbangan yang lebih baik. Ia dapat menggambarkan sutu benda yang kejadiannya sudah lalu (Piaget, 1997).

\section{Representation}

Perkembangan utama anak pada usia 2-7 tahun yang paling menonjol berupa kemampuan anak mempresentasikan objek dan peristiwa secara internal dalam 
struktur kognitifnya. Ada beberapa bentuk representasi anak pada tahap ini yaitu: 1) defrred imitation; 2) symbolic play; 3) drawing; 4) mental imegery; dan 6) spoken language.

1) Defferred Imitation adalah perilaku anak meniru terhadap apa yang dilihatnya baik itu benda, peristiwa atau suara. Perilaku meniru sebenarnya telah menunjukkan perkembangan kognitif anak.

2) Symbolic Play, pada tahap ini anak mengembangkan kemampuan membayangkan secara mental suatu obyek yang tidak ada. Simbolic play merujuk pada bentuk pernyataan, ide, pikiran, dan juga perhatian.

3) Drawing. Seiring perkembangan otak dan usianya, gambar tersebut mempresentasikan ide, gagasan secara terkoordinasi. Anak memaknai gambar sebagai pesan apa yang dilihat dan juga merupakan ekspresi buah pikiran. Misalnya anak menggambar anggota keluarganya secara lengkap (ada ayah, ibu, kakak, dan dirinya).

4) Mental Image adalah gambar internal (simbol) yang ada dalam struktur kognitif anak. Ia mempresentasikan objek dan pengalaman perseptual anak tentang apa yang dialami, meskipun tidak persis dengan apa yang dilihat dan dialami.

\section{Penalaran Alamiah}

Papalia., dkk (2009) terkait berpikir logis ia mengemukakan bahwa pada tahap praoperasional tumbuhnya pemahaman mengenai hubungan sebab-akibat, kemampuan mengklasifikasikan, dan pemahaman terhadap angka.

\section{Metode}

Metode yang digunakan dalam penelitian ini adalah kualitatif dengan pendekatan analisis deskriptif. Penelitian ini dilaksanakan di RA Bunayya Giwangan, khususnya anak usia 5-6 tahun atau kelas B. Jumlah anak dalam 1 kelas adalah 11. Namun sampel dalam penelitian ini berjumlah 5 orang. Pengambilan sampel tersebut berdasarkan pertimbangan orang tua yang menerapkan konsep digital parenting dalam keluarga. Teknik sampling dilakukan pada prapenelitian.

Sumber data dalam penelitian ini adalah orang tua yang menerapkan konsep digital parenting di keluarga dan anak usia 5-6 tahun yang berjumlah 5 orang, serta guru kelas yaitu Ibu Sukimah, S.Pd. Ke-5 anak tersebut berinisaial FKN, FAW, DAR, ERA, dan MFF. Untuk lebih jelasnya perhatikan tabel berikut ini:

Tabel 1 inisal anak dan orang tua yang menjadi sumber data dalam penelitian ini

\begin{tabular}{|c|l|c|l|c|}
\hline No. & \multicolumn{1}{|c|}{ Nama Anak } & Inisial & Nama Orang Tua & Inisial \\
\hline 1. & Fadhil Khoiri Nasywan & FKN & $\begin{array}{l}\text { Ahmad Fauzi } \\
\text { Eni Widyawati }\end{array}$ & $\begin{array}{c}\text { AF } \\
\text { EW }\end{array}$ \\
\hline 2. & $\begin{array}{l}\text { Fawwaz Atha Wafiq } \\
\text { Afandy }\end{array}$ & FAW & $\begin{array}{l}\text { Asnawi } \\
\text { Yessi Apriliana }\end{array}$ & $\begin{array}{c}\text { AS } \\
\text { YSA }\end{array}$ \\
\hline 3. & Dzikra Aquilla Rahaf & DAR & $\begin{array}{l}\text { Leo Tethos } \\
\text { Yulia Andriani }\end{array}$ & $\begin{array}{c}\text { LT } \\
\text { YA }\end{array}$ \\
\hline 4. & Elshopie R. Adityo & \multirow{2}{*}{ ERA } & $\begin{array}{l}\text { Imam Adityo } \\
\text { Nur Adhayati }\end{array}$ & IA \\
\hline 5. & Muhammad Fahmi Al Frizi & MFF & Eka Widya Astuti & EWA \\
\hline
\end{tabular}


Peneliti menggunakan teknik wawancara mendalam terhadap ibu, ayah dan anak; observasi terkait penerapan konsep digital parenting yang dilakukan peneliti di rumah; dan observasi terkait perkembangan berpikir logis anak di sekolah.

Peneliti melakukan penelitian selama dua bulan di lapangan. Peneliti mengumpulkan data (secara dokumentasi) terkait perkembangan bepikir logis yang ada pada guru kelas, penilaian anak sebelum peneliti melakukan penelitian hingga selesai penelitian. Data tersebut peneliti kumpulkan untuk memperkuat data yang diperoleh berdasarkan observasi.

\section{Hasil Penelitian dan Analisis}

\section{Penerapan Konsep Digital Perenting yang dilakukan Orang Tua terhadap Anak Usia 5-6 Tahun di RA Bunayya Giwangan}

Tabel 2. temuan subjek terkait penerapan konsep digital perenting

\begin{tabular}{|c|c|}
\hline $\begin{array}{l}\text { Nama } \\
\text { Anak }\end{array}$ & Penerapan Konsep Digital Perenting \\
\hline 1. FKN & $\begin{array}{l}\text { Saya yang menerapkan aturan dan kesepakatan terkait penggunaan gadget di rumah, } \\
\text { Saya membimbing dan mendampingi FKN bermain gadget, terkadang ayahnya atau } \\
\text { kakek/nenek. Saya megizinkan FKN menggunakan gadget karena apabila tidak } \\
\text { diberikan gadget maka FKN menangis. Ia bermain gadget maksimal } 15-30 \text { menit per } \\
\text { hari. FKN biasanya bermain game robot, balapan mobil, menonton Marsha and The } \\
\text { Bear, kartun binatang-binatang, dan lainnya. Saya menggunakan aplikasi parental } \\
\text { control "Dunia Anak". Selain itu, saya mendowloadkan FKN youtobe kids sebagai } \\
\text { pengganti Youtube biasa. Saya bertanya kepada FKN dari video yang telah } \\
\text { ditontonnya dan menanamkan nilai yang terkandung. Saya juga mengajak FKN untuk } \\
\text { bermain dengan temannya. }\end{array}$ \\
\hline 2. FAW & $\begin{array}{l}\text { "Saya dan papahnya menerapkan aturan dan ksepakatan terkait penggunaan gadget } \\
\text { di rumah. Kami nememani FAW bermain gadget. Saya megizinkan FAW } \\
\text { menggunakan gadget karena sebagai edukasi. Melalui gadget anak dapat melatih } \\
\text { berpikir, mewarnai, serta menambah wawasan. Ia bermain gadget maksimal 15-20 } \\
\text { menit per hari. FAW biasanya bermain game memancing, balapan mobil, Upin-Ipin, } \\
\text { dan Marsha and Bear. Saya biasanya menggunakan mode anak untuk membantu } \\
\text { mengontrol gadget anak. Selain itu, saya juga mengajak FAW untuk bermain dengan } \\
\text { temannya setelah bermain gadget." Namun, saya tidak bertanya kepada FAW terkait } \\
\text { nilai yang terkandung dalam video yang ditonton. }\end{array}$ \\
\hline 3. DAR & $\begin{array}{l}\text { Saya dan papanya yang menerapkan aturan dan kesepakatan terkait DAR } \\
\text { menggunakan gadget. Kami membimbing dan mendampingi DAR ketika bermain } \\
\text { gadget. Saya megizinkan DAR menggunakan gadget untuk menambah wawasan } \\
\text { anak, mewarnai, dan menambah kreatifitas DAR. Ia bermain gadget maksimal 15-30 } \\
\text { menit perhari. DAR biasanya bermain game mewarnai, nonton frozen, barbie, } \\
\text { Marsha And The Bear dan lainnya. Game dan videonya saya mendownloadkan, } \\
\text { terkadang DAR meminta download video baru, tetapi tetap saya yang } \\
\text { mendownloadnya. Saya menggunakan aplikasi parental control yaitu "Dunia Anak". } \\
\text { Setiap waktu bermain sudah habis, saya bertanya kepada DAR yang sudah dilihatnya } \\
\text { dari gadget, lalu mengajaknya untuk bermain dengan temannya. }\end{array}$ \\
\hline 4. ER & $\begin{array}{l}\text { Saya dan papanya mempunyai aturan dan kesepakatan terkait penggunaan gadget di } \\
\text { rumah. Saya dan papanya membimbing dan mendampingi ERA bermain gadget. } \\
\text { Saya megizinkan ERA menggunakan gadget karena kami sebagai orang tua tidak }\end{array}$ \\
\hline
\end{tabular}




\begin{tabular}{|l|l|}
\hline & $\begin{array}{l}\text { mungkin melarang ERA menggunakan hp dan bermain game dan video edukasi juga } \\
\text { dapat menambah wawasan dan kreatifitas anak. Ia bermain gadget maksimal 1 jam } \\
\text { per hari. ERA biasanya bermain hp setelah bagun tidur siang sebentar. ERA biasanya } \\
\text { menonton video "Diva",'Riska Si Gembul", Upin-Ipin, Marsha, dan game } \\
\text { mewarnai. Saya mendownloadkan youtube kids untuk ERA. Setelah bermain gadget } \\
\text { saya membiasakan ERA agar bermain dengan temannya. Saya juga menanamkan } \\
\text { nilai-nilai yang terkandung dalam video atau menanyakan ERA apa yang telah } \\
\text { ditonton atau dilihatnya. }\end{array}$ \\
\hline $5 . \quad$ MFF & $\begin{array}{l}\text { Saya dan MFF mempunyai aturan dan kesepakatan terkait penggunaan hp di rumah. } \\
\text { Saya membimbing dan mendampingi MFF ketika bermain gadget. Kadang-kadang } \\
\text { MFF juga bermain sendiri karena saya percaya terhadap MFF dan mengingatkan MFF } \\
\text { sebelum bermain handphone. Saya megizinkan MFF menggunakan gadget sebagai } \\
\text { edukasi dan dapat menambah wawasan dan kreatifitas anak, yang diperbolehkan } \\
\text { hanya yang edukasi. Ia bermain gadget maksimal 1 jam perhari. MFF biasanya main } \\
\text { gadget siang sebelum tidur dan sore setelah mandi. Saya yang mendownloadkan game } \\
\text { dan video untuk MFF, misalnya game berhitung, balap mobil, huruf hijiah, sholat, dan } \\
\text { video upin-ipin. Saya menggunakan fitur mode anak sebagai parental control. }\end{array}$ \\
\hline
\end{tabular}

\section{Pembahasan}

Temuan di atas menunjukkan bahwa orang tua dari anak usia 5-6 tahun di RA Bunayya Giwangan telah mengasuh anak dengan konsep digital parenting. Mereka membuat kesepakatan dengan anak terkait batasan dan waktu penggunaan gadget, tontotan atau game yang boleh diakses, menggunakan parental control, berusaha memahami teknologi, dan mengajak anak untuk bermain dengan temannya atau bermain sepedaan, atau lainnya. Meskipun terdapat perbedaan dari ke-5 orang tua di atas misalnya, batasan waktu menggunakan gadget, ada yang maksimal 1 jam, 30 menit atau 20 menit perhari; fitur parental parental control yang digunakan ada yang "mode anak", "dunia anak", youtube kids, dan lain-lain.

Berdasarkan analisis peneliti terhadap teori Herlina, dkk., (Herlina. dkk, 2018, p.23) sebagaimana yang telah dikemukakan sebelumnya terkait hal-hal yang dilakukan orang tua dalam menerapkan konsep digital parenting, bahwa penerapan konsep digital parenting yang dilakukan orang tua terhadap ke-5 subjek di atas mencakup: 1) menerapkan aturan dan kesepakatan dalam menggunakan gadget; 2) membimbing dan mendampingi anak; 3) menggunakan mode anak sebagai parental control; 4) menyeimbangkan waktu bermain anak. 


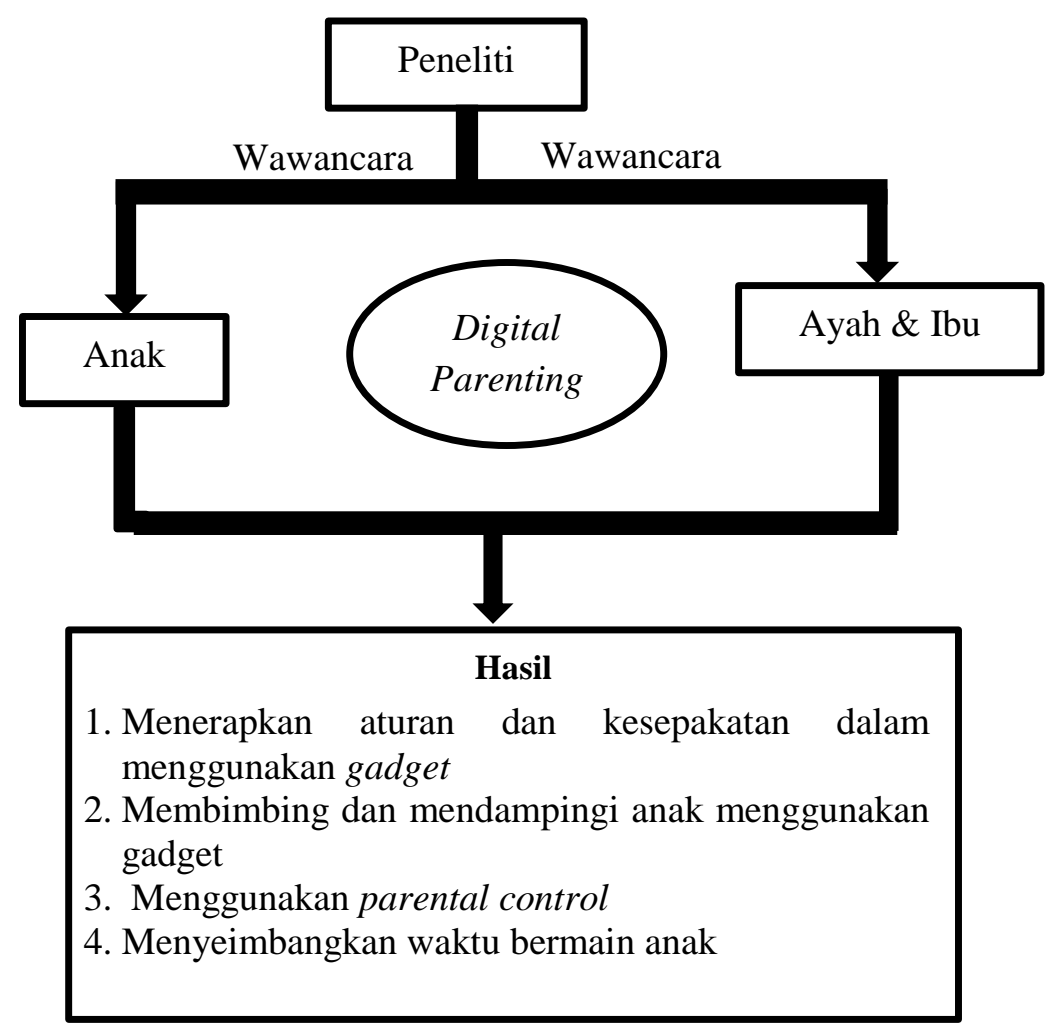

Bagan 1. hasil dari penerapan digital parenting yang dilakukan orang tua terhadap anak kelas B di RA Bunayya

\section{Peran Digital Parenting terhadap Perkembangan Berpikir Logis}

Tabel 3. temuan subjek terkait perkembangan berpikir logis

\begin{tabular}{|c|c|c|c|c|c|c|c|}
\hline \multirow{2}{*}{\multicolumn{2}{|c|}{$\begin{array}{c}\text { Aspek } \\
\text { Perkembangan }\end{array}$}} & \multirow{2}{*}{$\begin{array}{c}\text { Indikator/Sub tema } \\
\text { Rekreasi ke Kebun Binatang } \\
\text { Gembira Loka }\end{array}$} & \multicolumn{5}{|c|}{ KET } \\
\hline & & & FKN & FAW & DAR & ERA & MFF \\
\hline \multirow[t]{2}{*}{ 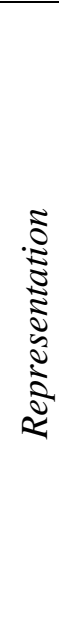 } & $\begin{array}{l}\text { Deffered } \\
\text { Imitation }\end{array}$ & $\begin{array}{ll}\text { 1. } & \text { Anak menirukan suara } \\
& \text { binatang yang ada di } \\
\text { Gembira Loka seperti } \\
\text { harimau, monyet, burung, } \\
\text { dan gajah } \\
\text { 2. } \\
\text { Anak dapat mengingat } \\
\text { binatang apa yang pernah } \\
\text { dilihat di kebun binatang } \\
\text { Gembira Loka. }\end{array}$ & $\mathrm{BSH}$ & BSH & $\mathrm{BSH}$ & $\mathrm{BSH}$ & BSH \\
\hline & $\begin{array}{l}\text { Symbolic } \\
\text { Play }\end{array}$ & $\begin{array}{l}\text { Anak dapat membuat minatur } \\
\text { dengan balok terkait bangunan } \\
\text { atau yang ada di Gembira loka. } \\
\text { Contohnya anak membuat } \\
\text { miniatur tempat pemebelian } \\
\text { tiket. }\end{array}$ & BSH & $\mathrm{BSH}$ & BSH & $\mathrm{BSH}$ & BSH \\
\hline
\end{tabular}




\begin{tabular}{|c|c|c|c|c|c|c|}
\hline Drawing & $\begin{array}{l}\text { 1. Anak mengambar binatang } \\
\text { atau objek lainnya yang ada di } \\
\text { Gembira Loka } \\
\text { 2. Anak memaknai dari apa yang } \\
\text { telah gambarnya }\end{array}$ & BSH & BSH & BSH & $\mathrm{BSH}$ & BSH \\
\hline $\begin{array}{l}\text { Mental } \\
\text { Imegery }\end{array}$ & $\begin{array}{l}\text { 1. Anak mengetahui macam- } \\
\text { macam pekerjaan (penjaga } \\
\text { loket dan guide) } \\
\text { 2. Anak mengetahui cara } \\
\text { merawat perlengkapan } \\
\text { rekreasi }\end{array}$ & BSH & BSH & $\begin{array}{l}\text { BSH } \\
\text { BSH }\end{array}$ & BSH & BSH \\
\hline $\begin{array}{l}\text { Penalaran } \\
\text { Ilmiah }\end{array}$ & $\begin{array}{ll}\text { 1. Anak dapat mengelompokkan } \\
\text { binatang berkaki empat yang } \\
\text { ada di Gembira Loka } \\
\text { (berdasarkan jumlah kaki) } \\
\text { 2. Anak dapat mengelompokkan } \\
\text { jenis binatang yang hidup di } \\
\text { air, udara, dan darat. } \\
\text { 3. Anak dapat mengelompokkan } \\
\text { binatang yang hidup yang } \\
\text { bertubuh besar dan kecil } \\
\text { 4. Anak dapat berhitung } \\
\text { sederhana }\end{array}$ & $\begin{array}{l}\mathrm{BSH} \\
\mathrm{BSH}\end{array}$ & BSH & $\mathrm{BSH}$ & $\mathrm{BSH}$ & BSH \\
\hline
\end{tabular}

Berdasarkan hasil observasi di atas menunjukkan bahwa dari kelima subjek, perkembangan berpikir logis mereka rata-rata sudah berkembang sesuai harapan. Berdasarkan teori Jean Piaget bahwa dari aspek defred imitation (perilaku anak meniru terhadap apa yang dilihatnya baik itu benda, peristiwa, suara, atau lainnya); simbolic play (anak mengembangkan kemampuan membayangkan secara mental suatu obyek yang tidak ada); drawing (coret-coretan atau gambar anak sudah terkoordinasi dan dapat memaknai gambar); mental imegery (anak mempresentasikan objek dan pengalaman perseptual anak tentang apa yang dialami, meskipun tidak persis dengan apa yang dilihat dan dialami); dan aspek perkembangan penalaran ilmiah, anak dapat mengklasifikasikan binatang berdasarkan ukuran, jumlah kaki, variasi, dan berhitung sederhana (Papalia. dkk, 2009, p.337).

Dengan demikian perkembangan berpikir logis anak telah berkembang sesuai harapan berdasarkan tahapan usia. Artinya, penggunaan gadget pada anak tidak berpengaruh negatif. Hal ini tidak lepas dengan adanya peran orang tua dalam mengasuh anak secara digital paerenting.

Tabel 3. Hasil observasi dan analisis terkait penggunaan gadget anak dan pengaruhnya terhadap berpikir logis

\begin{tabular}{|c|c|c|c|c|}
\hline $\begin{array}{c}\text { Subjek } \\
\text { Penelitian } \\
\end{array}$ & $\begin{array}{l}\text { Video yang } \\
\text { ditonton }\end{array}$ & $\begin{array}{l}\text { Pengaruh terhadap } \\
\text { Berpikir Logis }\end{array}$ & $\begin{array}{l}\text { Game yang } \\
\text { dimainkan }\end{array}$ & $\begin{array}{l}\text { Pengaruh terhadap } \\
\text { Berpikir Logis }\end{array}$ \\
\hline $\begin{array}{l}\text { FKN, FAW, } \\
\text { DAR, ERA } \\
\text { dan MFF }\end{array}$ & $\begin{array}{ll}\text { 1. Upin-Ipin } \\
\text { 2. Marsha and } \\
\text { The Bear } \\
\text { 3. Frozen } \\
\text { 4. Kartun } \\
\text { islami anak, } \\
\text { misalnya: }\end{array}$ & $\begin{array}{ll}\text { 1. } & \text { Sebagai } \\
\text { tontonan } \\
\text { edukasi } \\
\text { 2. } & \text { Menambah } \\
\text { wawasan dan } \\
\text { kreativitas } \\
\text { anak }\end{array}$ & $\begin{array}{ll}\text { 1. } & \text { Balapan mobil } \\
\text { 2. } & \text { Berhitung } \\
\text { 3. } & \text { Bermain } \\
\text { alfabet } \\
\text { 4. } \\
\text { Game } \\
\text { balon/kotak } \\
\text { warna }\end{array}$ & 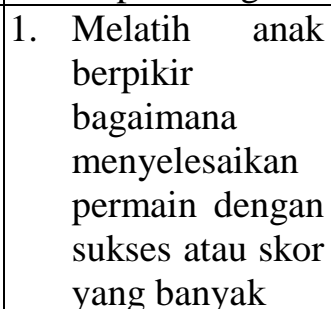 \\
\hline
\end{tabular}




\begin{tabular}{|c|c|c|c|c|}
\hline & $\begin{array}{l}\text { Diva, Dodo, } \\
\text { cerita nabi, } \\
\text { dll } \\
\text { 5. Lagu anak } \\
\text { 6. Video } \\
\text { kretivitas, } \\
\text { misalnya: } \\
\text { membuat } \\
\text { slem, } \\
\text { membuat } \\
\text { menara dari } \\
\text { lego atau } \\
\text { balok, dan } \\
\text { lainnya }\end{array}$ & 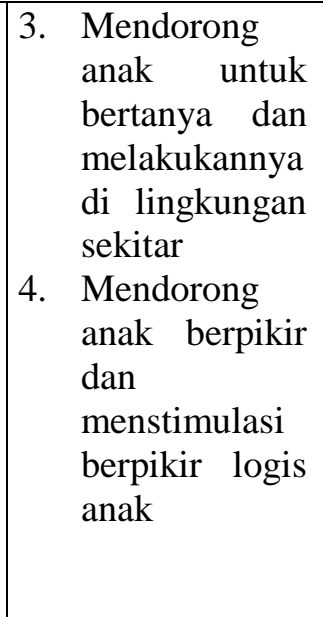 & \begin{tabular}{|ll} 
5. & Robot \\
6. & Supermarket \\
7. & Dan zombie \\
\end{tabular} & 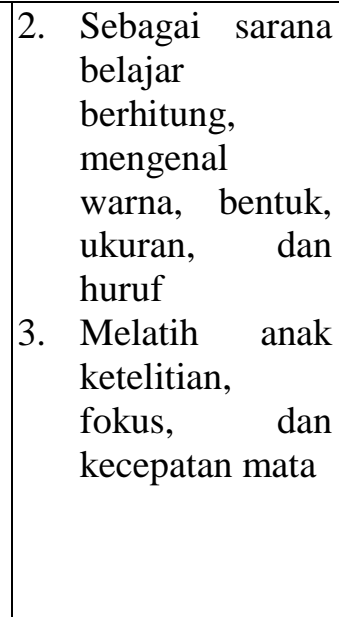 \\
\hline
\end{tabular}

Berdasarkan hasil observasi di atas menunjukkan bahwa tontonan dan game yang diakses kelima subjek merupan game dan video yang sesuai dengan usia anak. sehingga melalui bermain game dan menonton di gadget dapat menstimulasi berpikir anak, misalnya dengan game berhitung, game mengurutkan balok berdasarkan warna, berpir bagaiman anak menyelesaikan game dengan skor yang bagus, dan lain-lain.

Dengan demikian gadget tidak menggagu perkembangan kognitif anak khususnya aspek berpikir logis. Sehingga peran digital parenting terhadap perkembangan berpikir logis mencakup: 1) sebagai edukasi sekaligus hiburan, bermain sambil belajar; 2) menstimulasi berpikir logis anak; 3) memberi aturan dan dan pengawasan agar media digital atau gadget tidak mengganggu kosentrasi anak, tidak mengalami kesulitan tidur dan yang menghambat anak berpikir logis.

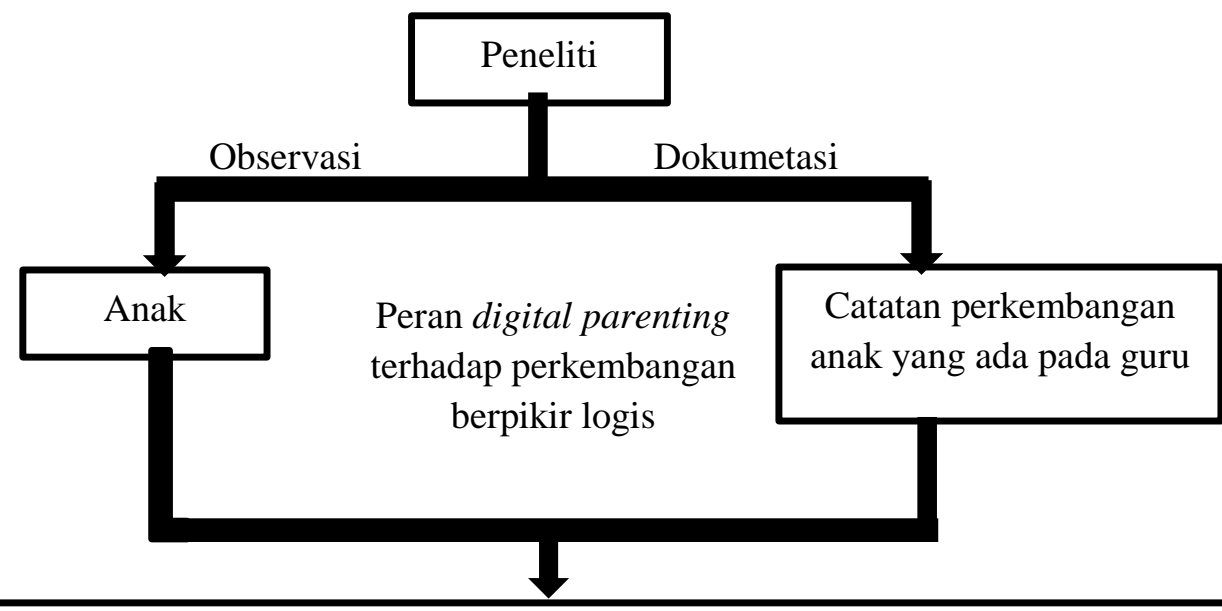

\section{Hasil}

1. Sebagai edukasi sekaligus hiburan, bermain sambil belajar

2. Menstimulasi berpikir logis anak, misalnya game berhitung, balapan, pilih objek sesuai gambar, dan lain-lain

3. Memberi aturan dan dan pengawasan agar media digital atau gadget tidak mengganggu kosentrasi anak, tidak mengalami kesulitan tidur dan yang menghambat anak berpikir logis

Bagan 2. hasil dari peran digital parenting terhadap perkembangan berpikir logis anak usia 5-6 tahun di RA Bunayya 


\section{Kesimpulan}

Berikut ini kesimpulan dari hasil penelitian terkait "Peran Digital Parenting terhadap Perkembangan Perilaku Prososial dan Berpikir Logis Anak Usia 5-6 Tahun":

1. Penerapan konsep digital parenting yang dilakukan orang tua terhadap anak usia 5-6 tahun di RA Bunayya meliputi: menetapkan aturan dan kesepakatan terkait penggunaan gadget; membimbing dan mendampingi anak saat menggunakan gadget; menggunakan parental control; dan orang tua membiasakan anak bermain dengan temannya setelah bermain gadget agar anak dapat bersosialsasi dengan temannya.

2. Peran digital parenting terhadap perkembangan berpikir logis anak usia 5-6 tahun di RA Bunayya meliputi: sebagai edukasi sekaligus hiburan, bermain sambil belajar; menstimulasi berpikir logis anak; memberi aturan dan dan pengawasan agar perangkat digital atau gadget tidak mengganggu kosentrasi anak dan yang menghambat anak berpikir logis.

\section{Referensi}

Alia, Tesa. (2018). "Pendampingan Orang Tua pada Anak Usia Dini dalam Penggunaan Teknologi Digital", dalam A Journal of Language, Literature, Culture, and Education POLYGOT, 14, (1), 65-78.

Alucyna, "Menakar Teknologi dan Perkembangan Kognitif untuk Media Pembelajaran Anak Usia Dini", dalam Al Hikmah Proceedings on Islamic Early Childhood Education, 1, (1), 41-52.

Bagus, Ramadhan. "Inilah Perkembangan Digital Indonesia Tahun 2018”. Dalam http://www.goodnewsfromindonesia.id. diakses pada tanggal 24 November 2018.

Bloom, Benjamin S. (1986). "The Hands and Feet of Genius Automaticity, Education Leadership". http://www.ascd.org/ASCD/pdf/journals/ed_lead/el_198602_bloom.pdf. diakses pada tanggal 24 Januari 2019.

Herlina, Dyna, dkk. (2018). Digital Parenting: Mendidik Anak di Era Digital. Yogyakarta: Samudra Biru.

Kurniasari, Intan, dkk. (2013). "Penggunaan Media Alam Sekitar dan Kemampuan Berpikir Logis Anak Usia Dini", dalam Edu-Sains, 2, (2), 14-21.

Laely, Khusnul, dkk. (2017). "Parenting Pengasuhan di Era Digital dalam Rangka Mendukung Terwujudnya PKBM (Pusat Kegiatan Belajar Masyarakat) di Daerah Miskin", dalam University Reseach Colloquium, 2, (7), 1-8.

Mascheroni, Giovanna, dkk. (2018). "Digital Parenting: The Challengs for Families in The Digital Age". Nordocom University of Gothenburg: The International Clearinghouse on Children, Youth and Media.

Minutos, Mega. 2016. The Creative Curriculum for Preschool. Teaching Strategis: Colombus.

Papalia., dkk. (2009). Human Development, terj. Brian Marswendy. Jakarta: Salemba Humanika.

Permendikbud Nomor 137 Tahun 2014 tentang Standar Nasional Pendidikan Anak Usia Dini.

Piaget, Jean. 1997. The Psychology of Intelegence. Edisi ke-7. Madrid: Ediciones Morata. 
Rode, Jennifer A., (2009). "Digital Parenting: Designing Children's Safety", dalam British Computer Society, London, 6, (12), 244-251.

Santrock, Jhon, W. 2002. Life-Span Development, terj. Achmad Chusairi. Edisi ke-5. Jilid 1. Jakarta: Erlangga.

Sukiman. dkk. (2016). Seri Pendidikan Orang Tua: Mendidik Anak Di Era Digital. Jakarta: Kementerian Pendidikan dan Kebudayaan.

Yolanda, Reid, Chassiakos et al. (2016). "Children and Adolescent and Digital Media. American Academy of Pediatrics", 138, (5), 62-78.

Yurdakul, Isil Kabakci, dkk, (2013). "Dijital Ebeveylinlik ve Degisen Roller", dalam Gaziantep University Journal of Sosial Science, 4, (12). 883-896. 